\title{
Validation of SOS-lux Microbial Biosensors for Mutagenicity Assessment: Mitomycin-C as a Model Compound
}

Hani A Alhadrami ${ }^{1,2 *}$ and Graeme I Paton ${ }^{1,3}$

${ }^{1}$ Faculty of Applied Medical Sciences, King Abdulaziz University, P.O. Box 80324, Jeddah-21589, Kingdom of Saudi Arabia

${ }^{2}$ Institute of Biological and Environmental Sciences, Cruickshank Building, University of Aberdeen, Aberdeen AB24 $3 U U$, United Kingdom

${ }^{3}$ Remedios Limited, Balgownie Technology Centre, Balgownie Drive, Aberdeen, AB22 8GW, United Kingdom

\begin{abstract}
Human health protection requires relating the bioaccessible concentration of a mutagen with the corresponding likely harm that could be caused through exposure. This requires designating the target receptor in need of protection, and a quantitative understanding of the likely pathways for mutagen availability. In this study, young children were selected as target receptors because of their tendency to directly ingest soils. Most data used to characterise a chemical mutagenicity has been extrapolated from rat-based assays using chemical ingestion or direct injection procedures. Mitomycin $\mathrm{C}$ was selected as a relevant model compound and extracted using an established in vitro digestion technique. A range of mutagenic bioassays (i.e. SOS-Iux based microbial biosensors and Salmonella mutagenicity assay) were calibrated and optimised in aqueous samples, before being applied to soil extracts. The biosensors were consistently as sensitive and responsive as the traditional Salmonella assay, however, the use of microbial biosensors offered speed and ease of analysis. The data presented confirm that the in vitro digestion bioassay enabled a rapid and inexpensive technique for deriving critical values for the protection of humans exposed to soil borne mutagenic pollutants.
\end{abstract}

Keywords: SOS-lux biosensors; Salmonella assay; In vitro digestion; Mutagenicity; Bioluminescent bacteria; Mitomycin C

\section{Introduction}

Soil ingestion (both directly and through vegetable consumption) is a significant pathway by which pollutants enter the human body [1]. Permissible concentrations of ingested soil pollutants have been derived from animal studies (direct feeding or injection), and translated to humans. Such extrapolations often fail to consider the bioaccessible and bioavailable fractions of pollutants and their relative toxicity [2]. These extractions quantify the bioaccessible fraction of soil pollutants by simulating the oral exposure pathway for children (the most sensitive human receptors). The term, bioaccessible, in the context of human ingestion, is defined as the fraction of a substance that is soluble in the gastrointestinal environment and available to human biochemical processing [3].

Environmental mutagens are external agents that when activated, increase the rate of mutation in cells. Chemical analysis alone is unable to predict the biological impacts, antagonistic or synergistic effects in a mixture of mutagenic pollutants, nor to address the significance of bioavailability in terms of pollutant assimilation [4]. These shortcomings have required the development and application of rapid assays to screen large numbers of samples from environmental matrices.

Luminescence-based bacterial biosensors have been developed to detect a variety of mutagens [5]. Biosensors for mutagenicity assessments have been used due to their simplicity and sensitivity [6]. The SOS-lux based microbial biosensors have a promoter less luxoperon (luxCDABE) under control of the SOS-dependant col promoter, and thus, its synthesis is regulated by the SOS-system [7]. An exposure to a target analyte leads to an increase in the concentration of luciferase and bioluminescence. Subsequently, bioluminescence expression is proportional to the mutagenicity of the agent.

The Salmonella mutagenicity assay (Ames assay) is the most widely accepted bacterial assay for the screening and identification of mutagenic compounds [8]. Independent studies have shown a correlation between mutagenicity in the Salmonella assay and carcinogenicity in mammals
[9]. The assay uses a number of Salmonella strains with pre-existing mutations that disable the cells from synthesising histidine, thus inhibiting growth. Fresh mutations at the site of these pre-existing mutations can restore the gene's function and allow the cells to resynthesis histidine. Enumerations of these mutated colonies in the absence of histidine enable an assessment of mutagenicity [10]. The assay is reliable but laborious and requires working with Salmonella strains, which are classified as human pathogen.

In this study, MMC was extracted using a human digestion simulation procedure (the in vitro bioassay), and the mutagenicity of the extracted samples was measured using the Salmonella assay and SOS-lux based microbial biosensors. This enabled an overall evaluation of the optimised assays, before working with a complex environment like soil. MMC was then amended into soil which extracted using the in vitro bioassay, followed by comparative mutagenic assays. Furthermore, the effect of the simulated gastrointestinal constituents on the mutagenicity of MMC was assessed. The aim of this work was to validate the performance of microbial biosensors for mutagenicity assessment and consider the relevance of the in vitro bioassay in assessing pollutant exposure.

\section{Materials and Methods}

\section{Stock solutions and soil preparation}

*Corresponding author: Hani A Alhadrami, Institute of Biological and Environmental Sciences, Cruickshank Building, University of Aberdeen, Aberdeen AB24 3UU, United Kingdom, Tel: +966 5055 45275; E-mail: hani.alhadrami11@aberdeen.ac.uk

Received August 13, 2013; Accepted September 28, 2013; Published October 06, 2013

Citation: Alhadrami HA, Paton GI (2013) Validation of SOS-/ux Microbial Biosensors for Mutagenicity Assessment: Mitomycin-C as a Model Compound. J Biosens Bioelectron 4: 142. doi: 10.4172/2155-6210.1000142

Copyright: (C) 2013 Alhadrami HA, et al. This is an open-access article distributed under the terms of the Creative Commons Attribution License, which permits unrestricted use, distribution, and reproduction in any medium, provided the original author and source are credited. 
Mutagenicity testing using the Salmonella assay and the SOSlux biosensors was performed against a range of doses of mitomycin C (MMC). MMC was purchased from Sigma (St.Louis, MO, USA), and dissolved in reverse osmosis water. Soil (sandy loam) of Insch Association/Insch Series (North-East Scotland) was collected to a depth of $50 \mathrm{~cm}$, passed through a $2 \mathrm{~mm}$ stainless steel sieve, thoroughly mixed and amended with MMC to give final concentrations of 1,10 and 50 $\mu \mathrm{g} \mathrm{MMC} / \mathrm{g}$ dry weight $(\mathrm{dw})$ soil using standard procedures [11]. Soil amended with MMC was extracted by the in vitro digestion extraction and then assayed. The dose selection of MMC for soil amendment was based upon the dose response curves of MMC, which tested with the Salmonella assay and the SOS-lux biosensors. Un-amended soil (MMC free soil) was used as a negative control.

\section{The in vitro bioassay}

The sequential and the compartmental in vitro digestion extractions were carried out for soils amended with MMC. The sequential in vitro digestion assay was performed as described by Oomen et al. [1]. The compartmental approach was performed by extracting soil samples separately in each digestive compartment (i.e. saliva, gastric and duodenal). Synthetic gastrointestinal juices were simulated as described by Oomen et al. [1]. In summary, the saliva extraction was performed by adding $9 \mathrm{ml}$ of synthetic saliva ( $\mathrm{pH} 6.5 \pm 0.2$ ) to $0.6 \mathrm{~g}$ soil. The mixture was rotated for $5 \mathrm{~min}$ using an end-over-end shaker. The samples were centrifuged for $10 \mathrm{~min}$ at $1730 \mathrm{~g}$ and $37^{\circ} \mathrm{C} \pm 2^{\circ} \mathrm{C}$. The "digested soil" (the pellet) was discarded and the supernatant (the chyme) removed and stored at $4^{\circ} \mathrm{C}$. Gastric extraction was performed by adding 13.5 $\mathrm{ml}$ of the synthetic gastric juice $(\mathrm{pH} 1.1 \pm 0.1)$ to $0.6 \mathrm{~g}$ soil, and the mixture was mixed by end-over-end shaking for $2 \mathrm{~h}$, centrifuged and stored at $4^{\circ} \mathrm{C}$. The intestinal extraction was carried out by adding $27 \mathrm{ml}$ of the synthetic duodenal juice ( $\mathrm{pH} 7.8 \pm 0.2)$ and $9 \mathrm{ml}$ of the synthetic bile $(\mathrm{pH} 8.0 \pm 0.2)$ to $0.6 \mathrm{~g}$ soil. The mixture was rotated for $2 \mathrm{~h}$ and centrifuged as above. The digestive juices were maintained at $37 \pm 2^{\circ} \mathrm{C}$ in a water bath, prior to assay.

\section{The Ames assay}

The standard plate incorporation procedure described by Maron and Ames [12] was used for the Ames assay. In brief, Salmonella strains TA98, TA100 and TA102 were grown overnight in $150 \mathrm{ml}$ Erlenmeyer flask containing $25 \mathrm{ml}$ Oxoid nutrient broth at $37^{\circ} \mathrm{C}$ in an orbital shaker at $150 \mathrm{rpm}$ with appropriate antibiotics $\left(25 \mu \mathrm{g} \mathrm{ml}^{-1}\right.$ ampicillin for TA98 and TA100, and $2 \mu \mathrm{g} \mathrm{ml}^{-1}$ tetracycline for TA102). The cultures were incubated until they reached an absorbance of 1.0 at $660 \mathrm{~nm}$ (corresponding to $1-2 \times 109 \mathrm{CFU} \mathrm{ml} \mathrm{m}^{-1}$ ). Two $\mathrm{ml}$ of melted top agar supplemented with histidine and biotin solution was distributed into sterile glass tubes, and placed in a $45^{\circ} \mathrm{C}$ water bath. A hundred $\mu \mathrm{l}$ of MMC extracted by the in vitro bioassay and $100 \mu \mathrm{l}$ of the tester strain was added, gently mixed by vortexing, and poured onto the surface of Minimal Glucose Agar plate. The plates were gently tilted and rotated to obtain an even distribution, placed onto a level surface to solidify and incubated at $37^{\circ} \mathrm{C}$ for $48 \mathrm{~h}$. Following the incubation, the revertant colonies were enumerated on a Gallenkamp colony counter. Appropriate reagent and negative controls [12] were included to enumerate the spontaneous revertants.

The assay was conducted using triplicate of each sample and control. Salmonella typhimurium TA98, TA100 and TA102 were obtained from Molecular Toxicology Inc. (MD, USA). The strains were maintained and stored according to standard protocols [10].

\section{SOS-lux biosensors}

Biosensor strains E. coli $\mathrm{K} 12 \mathrm{C} 600$ and E. coli DPD1718 were obtained from Rettberg et al. [7] and Vankemmelbeke et al. [13], respectively. Overnight cultures were grown on $\mathrm{LB}$ media at $37^{\circ} \mathrm{C}$ in an orbital shaker at $150 \mathrm{rpm}$ in the presence of the appropriate antibiotics $\left(50 \mu \mathrm{g} \mathrm{ml}^{-1}\right.$ ampicillin for E. coli $\mathrm{K} 12 \mathrm{C} 600$ and $30 \mu \mathrm{gml}^{-1}$ chloramphenicol for E. coli DPD1718). Overnight cultures were diluted 1:50 in LB broth, and grown at $37^{\circ} \mathrm{C}$, until they reached the appropriate pre-optimised optical density $\left(0.3\right.$ at $\mathrm{OD}_{550}$ for E. coli $\mathrm{K} 12 \mathrm{C} 600$ and 0.4 at $\mathrm{OD}_{492}$ for $E$. coli DPD1718). A negative control of $100 \mu \mathrm{l} \mathrm{MilliQ}$ water or $100 \mu \mathrm{l}$ sample was mixed with $900 \mu \mathrm{l}$ of overnight culture in $3 \mathrm{ml}$ luminometer cuvettes. Bioluminescence was measured using a Jade bench-top luminometer (Labtech International, Uckfield, UK), over a period of $300 \mathrm{~min}$, with readings taken every $30 \mathrm{~min}$.

\section{Analytical techniques for MMC}

MMC was analytically measured after the in vitro digestion extractions carried out for soils amended with MMC. The method adopted was modified from Metha et al. [14]. Soil samples (2 $g \pm 0.01)$ were grounded with $2 \mathrm{~g}$ of anhydrous sodium sulphide. Samples from the in vitro digestion assay were transferred to $30 \mathrm{ml}$ Wheat on vials and $15 \mathrm{ml}$ of methanol was added. The samples were sonicated, and for $6 \mathrm{~h}$ placed on an over and under shaker. Samples were centrifuged at $4^{\circ} \mathrm{C}$ for $10 \mathrm{~min}$ in glass centrifuge tubes. The sample was filtered through alumina and transferred to $1.5 \mathrm{ml}$ HPLC sealed glass vials for analysis. Analysis was performed at $365 \mathrm{~nm}$ by HPLC (Thermoquest; Thermo Separation Products, San Jose, CA) on an octadecylsilicate column (15 $\mathrm{cm} 4.6 \mathrm{~mm}$, i.e. particle diameter $5 \mathrm{ml}$ ), at a flow rate of $1.0 \mathrm{ml} \mathrm{min}^{-1}$.

The mobile phase was an acetonitrile: water mix with an elution gradientof 30:70 initially for $10 \mathrm{~min}$; then increased to 60:40, over 10 min, and finally increased to $90: 10$ over $5 \mathrm{~min}$.

\section{Statistical analysis}

Each sample was tested in triplicate. Statistical analysis was performed using Minitab 15 for Windows. A result with $p \leq 0.05$ was considered significant. The two fold increase rule was applied for the Salmonella assay to evaluate the mutagenicity of the tested compounds [12]. For the biosensors, a compound was considered a mutagen if there was at least a two fold increase in the bioluminescence response relative to the negative control value $[15,16]$. If the bioluminescence values decreased during the incubation time, the sample was more likely to be cytotoxic [7]. If bioluminescence was not induced and the cell growth was comparable to that of the untreated control, the test sample was assumed to be neither mutagenic nor cytotoxic.

\section{Results}

\section{Mutagenicity response of the Salmonella assay to MMC tested in the aqueous phase}

Salmonella strain TA102 was the most sensitive strain to detect the mutagenicity of MMC (Table 1). Salmonella strains TA98 and TA100 were, by comparison, insensitive to MMC, as the numbers of histidine revertants were not twice the numbers of the spontaneous revertants (Table 1). A significant mutagenic response was detected for MMC tested with TA102, and extracted in the saliva and the duodenal compartments. There was no significant mutagenic response detected for MMC extracted in the gastric and in the sequential compartments (Table 1). To further investigate the reason for that, the $\mathrm{pH}$ of the two compartments were buffered, and the mutagenicity was re-evaluated 
Citation: Alhadrami HA*, Paton GI (2013) Validation of SOS-lux Microbial Biosensors for Mutagenicity Assessment: Mitomycin-C as a Model Compound. J Biosens Bioelectron 4: 142. doi: 10.4172/2155-6210.1000142

Page 3 of 6

\begin{tabular}{|c|c|c|c|c|}
\hline \multirow[t]{2}{*}{ Sample } & \multirow[t]{2}{*}{ Dose $(\mu \mathrm{g} / \text { Plate })^{\mathrm{B}}$} & \multicolumn{3}{|c|}{ Number of revertants/plate (mean $\pm \mathrm{SE})^{\mathrm{D}}$} \\
\hline & & TA98 & TA100 & TA102 \\
\hline \multirow[t]{3}{*}{ Saliva } & $0^{c}$ & $38 \pm 4^{E}$ & $151 \pm 9^{\mathrm{E}}$ & $449 \pm 29^{E}$ \\
\hline & 0.5 & $4 \pm 1$ & $0 \pm 0$ & $1836 \pm 57^{F}$ \\
\hline & 1 & $1 \pm 0$ & $13 \pm 1$ & $2098 \pm 155^{F}$ \\
\hline Positive control ${ }^{\mathrm{A}}$ & & $1675 \pm 0^{F}$ & $484 \pm 29 \mathrm{~F}$ & $2151 \pm 95^{\mathrm{F}}$ \\
\hline \multirow[t]{3}{*}{ Gastric } & $0^{c}$ & $38 \pm 4^{E}$ & $151 \pm 9^{\mathrm{E}}$ & $449 \pm 29^{\mathrm{E}}$ \\
\hline & 0.5 & $42 \pm 3$ & $61 \pm 9$ & $502 \pm 21$ \\
\hline & 1 & $44 \pm 5$ & $84 \pm 4$ & $468 \pm 15$ \\
\hline Positive controlA & & $1675 \pm 0^{F}$ & $484 \pm 29^{F}$ & $2151 \pm 95$ \\
\hline \multirow[t]{3}{*}{ Duodenal + Bile } & $0^{c}$ & $38 \pm 4^{E}$ & $151 \pm 9^{\mathrm{E}}$ & $449 \pm 29^{E}$ \\
\hline & 0.5 & $9 \pm 2$ & $13 \pm 2$ & $1800 \pm 74^{F}$ \\
\hline & 1 & $0 \pm 0$ & $54 \pm 5$ & $1699 \pm 116^{F}$ \\
\hline Positive controlA & & $1675 \pm 0^{F}$ & $484 \pm 29 F$ & $2151 \pm 95^{F}$ \\
\hline \multirow[t]{3}{*}{ Sequential } & $0^{c}$ & $38 \pm 4^{E}$ & $151 \pm 9^{E}$ & $449 \pm 29^{E}$ \\
\hline & 0.5 & $37 \pm 1$ & $166 \pm 5$ & $524 \pm 31$ \\
\hline & 1 & $38 \pm 3$ & $170 \pm 10$ & $473 \pm 19$ \\
\hline Positive control A & & $1675 \pm 0^{F}$ & $484 \pm 29^{F}$ & $2151 \pm 95^{F}$ \\
\hline
\end{tabular}

APositive Control: TA98-Daunomycin (6 $\mu$ g/Plate); TA100-Sodium Azide (1.5 $\mu$ g/Plate); TA102-Mitomycin C $(0.5 \mu \mathrm{g} / \mathrm{Plate})$. ${ }^{\mathrm{B} C o n c e n t r a t i o n}$ based on $100 \times 15-m m$ Petri dish containing 20 to $25 \mathrm{ml}$ of MG agar. The doses of the tested mutagens were expressed as $\mu \mathrm{gg} / \mathrm{plate}$ (Maron and Ames, 1983; Mortelmans and Zeiger, 2000). ${ }^{\mathrm{C} N e g a t i v e}$ control: Filter sterilised water. ${ }^{D}$ Number of histidine revertants per plate: Mean values of at least three plates \pm standard error (SE). ${ }^{E N u m b e r s ~ i n ~ i t a l i c, ~ b o l d f a c e ~ a n d ~}$ underlined represent the number of spontaneous revertants colonies for: TA98 (30-50), TA100 (120-200) and TA102 (117-530) (Maron and Ames, 1983). FNumbers in boldface represent two fold increase or more in the number of revertant colonies over the solvent controls (spontaneous revertants), which was an indication of a significant mutagenic response.

Table 1: The number of reverse mutants of S. typhimurium TA98, TA100 and TA102 after exposure to MMC Samples were analysed in the aqueous phase after extraction by the in vitro procedure.

\begin{tabular}{|c|c|c|}
\hline Sample & Dose ( $\mu \mathrm{g} / \mathrm{Plate})$ & $\begin{array}{l}\text { Number of revertants/plate } \\
\quad(\text { mean } \pm \mathrm{SE})^{\mathrm{c}}\end{array}$ \\
\hline \multirow{3}{*}{$\begin{array}{c}\text { Gastric } \\
(\mathrm{pH} \mathrm{1.07)}\end{array}$} & $0^{B}$ & $467 \pm 12^{\mathrm{D}}$ \\
\hline & 0.5 & $505 \pm 20$ \\
\hline & 1 & $424 \pm 8$ \\
\hline $\begin{array}{l}\text { Positive } \\
\text { control }^{\mathrm{A}}\end{array}$ & & $1223 \pm 117^{E}$ \\
\hline \multirow{3}{*}{$\begin{array}{c}\text { Gastric } \\
(\mathrm{pH} 7.4)\end{array}$} & $0^{B}$ & $467 \pm 12^{D}$ \\
\hline & 0.5 & $510 \pm 11$ \\
\hline & 1 & $493 \pm 27$ \\
\hline $\begin{array}{l}\text { Positive } \\
\text { controlA }^{A}\end{array}$ & & $1223 \pm 117^{E}$ \\
\hline \multirow{3}{*}{$\begin{array}{c}\text { Sequential } \\
(\mathrm{pH} 5.8)\end{array}$} & $0^{B}$ & $467 \pm 12^{\mathrm{D}}$ \\
\hline & 0.5 & $507 \pm 8$ \\
\hline & 1 & $475 \pm 27$ \\
\hline $\begin{array}{l}\text { Positive } \\
\text { control }^{\mathrm{A}}\end{array}$ & & $1223 \pm 117^{E}$ \\
\hline \multirow{3}{*}{$\begin{array}{c}\text { Sequential } \\
(\mathrm{pH} 7.5)\end{array}$} & $0^{B}$ & $467 \pm 12^{D}$ \\
\hline & 0.5 & $511 \pm 12$ \\
\hline & 1 & $480 \pm 5$ \\
\hline $\begin{array}{l}\text { Positive } \\
\text { control }^{\mathrm{A}}\end{array}$ & & $1223 \pm 117^{E}$ \\
\hline
\end{tabular}

APositive Control for TA102- Mitomycin C $(0.5 \mu \mathrm{g} /$ plate $) .{ }^{B}$ Negative control: Filter sterilised water. ${ }^{C}$ Number of histidine revertants per plate: Mean values of at least three plates \pm standard error (SE). DNumbers in italic, boldface and underlined represent the number of spontaneous revertants colonies for TA102 (117-530). ENumbers in boldface represent two fold increase or more in the number of revertant colonies over the solvent controls (spontaneous revertants), which was an indication of a significant mutagenic response.

Table 2: The number of reverse mutants of S. typhimurium TA102 after exposure to MMC Samples were analysed in the aqueous phase after extraction by the in vitro procedure (buffered and un-buffered samples).

with TA102 (Table 2). The $\mathrm{pH}$ values of samples extracted in the gastric juice were increased from $1.07 \pm 0.10$ to $7.4 \pm 0.10$. Similarly, the $\mathrm{pH}$ values were increased from $6.8 \pm 0.20$ to $7.5 \pm 0.10$ for samples extracted by the sequential in vitro bioassay. There was no significant mutagenic response for MMC extracted in the gastric, and in the

sequential compartments for the buffered ( $\mathrm{pH}$ values $7.4 \pm 0.10$ and 7.5 $\pm 0.10)$ and un-buffered ( $\mathrm{pH}$ values $1.07 \pm 0.10$ and $6.8 \pm 0.20$ ) samples (Table 2).

\section{Mutagenicity response of SOS-lux biosensors toMMC tested in the aqueous phase}

The biosensor (E. coli K12C600) dose response for the negative control (MilliQ water) was significantly different to the samples treated with MMC and extracted in the saliva and the duodenal compartments (Figure 1). The biosensor E. coli K12C600 was not significantly induced by samples treated with MMC and extracted by the gastric and the sequential in vitro bioassay (Figure 1). These results suggested that the biosensor E. coli $\mathrm{K} 12 \mathrm{C} 600$ was induced by MMC extracted in the saliva and in the duodenal compartments, whereas MMC extracted by the gastric and the sequential in vitro bioassays was no longer a mutagen, as it was not able to induce E. coli K12C600 (Figure 1). The same results were observed for E. coli DPD1718 (Figure 2) (saliva and in the duodenal compartments, but not the gastric and in the sequential compartments). These findings were compatible with the results reported with the biosensor E. coli $\mathrm{K} 12 \mathrm{C} 600$, suggesting that MMC was not a mutagen, once it passed through the gastric compartment of the simulated human gastrointestinal juices (Figures 1 and 2).

\section{Mutagenicity response of the Salmonella assay to MMC amended soil}

The Salmonella mutagenicity assay responded significantly to Insch soils amended with 10 and $50 \mu \mathrm{g} \mathrm{MMC} / \mathrm{g} \mathrm{dw}$ soil (Table 3). For Insch soil extracted with the gastric and the sequential in vitro extractions (Table 3), no significant mutagenic response was observed. The Salmonella results confirmed that MMC had a mutagenic effect at a concentration of $10 \mu \mathrm{g} \mathrm{MMC/g} \mathrm{dw} \mathrm{soil} \mathrm{and} \mathrm{above,} \mathrm{when} \mathrm{extracted}$ with synthetic saliva and duodenal juices. At the concentrations tested, MMC had no mutagenic impact on the Salmonella strain TA102 in the sequential and the gastric in vitro extractions due to the denaturing of $\mathrm{MMC}$ at the extraction $\mathrm{pH}$ value (Table 3 ). 
Citation: Alhadrami HA*, Paton GI (2013) Validation of SOS-lux Microbial Biosensors for Mutagenicity Assessment: Mitomycin-C as a Model Compound. J Biosens Bioelectron 4: 142. doi: 10.4172/2155-6210.1000142

Page 4 of 6
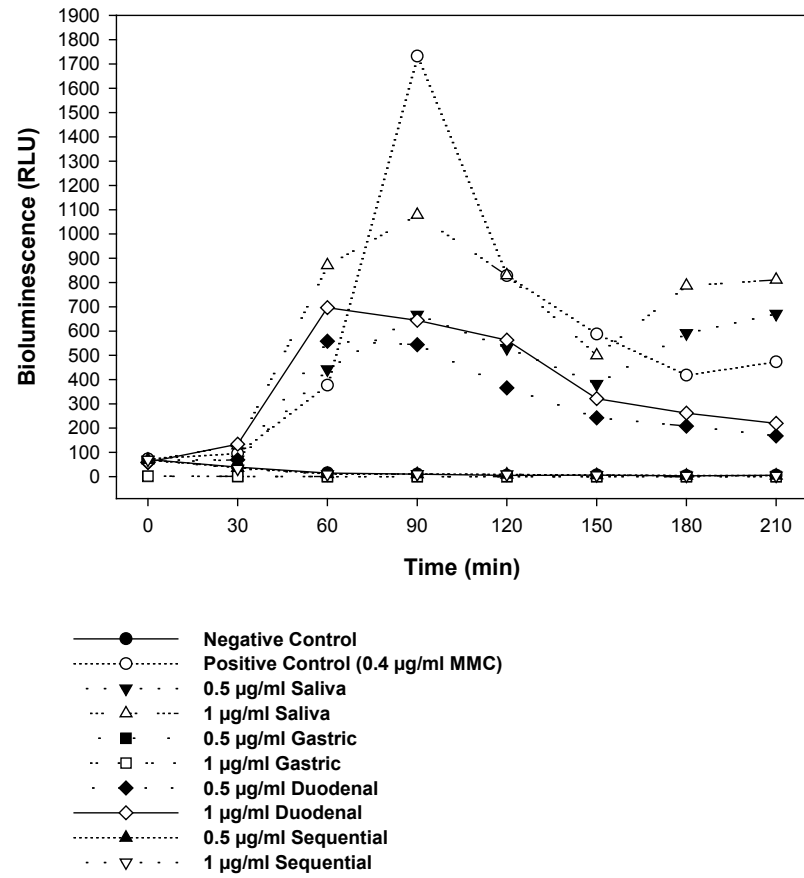

Figure 1: Mutagenicity response of the SOS-Iux microbial biosenso Escherichia coli $\mathrm{K} 12 \mathrm{C} 600$ to $\mathrm{MMC}$ in the aqueous phase and extracted by the in vitro extraction. The biosensor was only induced by samples treated with 0.5 and $1 \mu \mathrm{g} / \mathrm{ml} \mathrm{MMC,} \mathrm{and} \mathrm{extracted} \mathrm{in} \mathrm{the} \mathrm{saliva} \mathrm{and} \mathrm{the} \mathrm{duodenal}$ compartments.
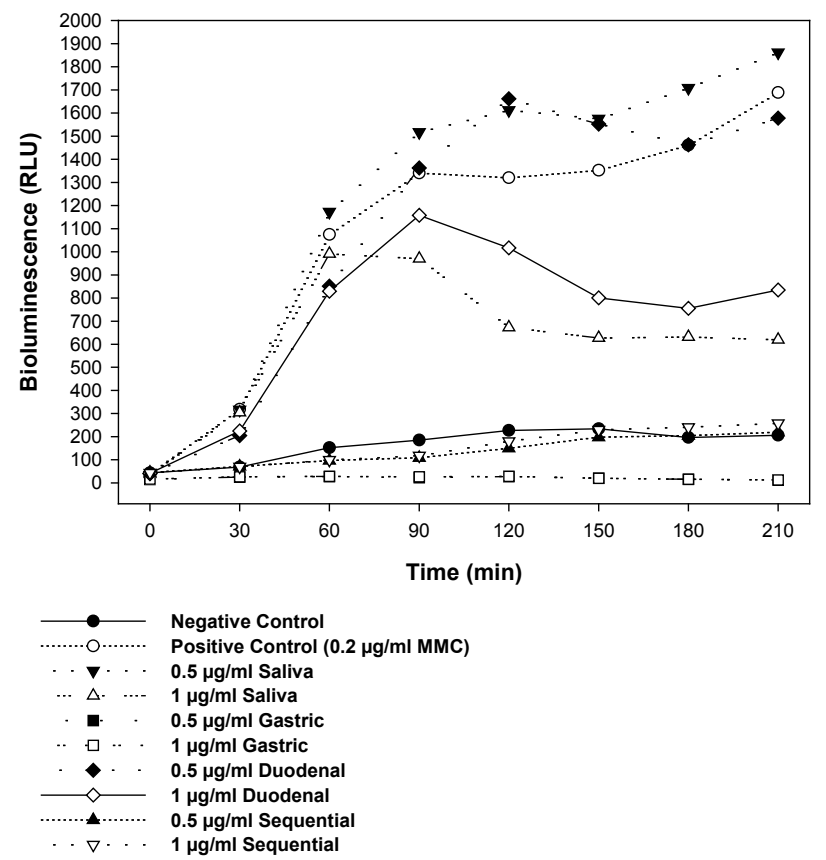

Figure 2: Mutagenicity response of the SOS-lux microbial biosensor Escherichia coli DPD1718 to MMC tested in the aqueous phase and extracted by the in vitro extraction. The biosensor was only induced by samples treated with 0.5 and $1 \mu \mathrm{g} / \mathrm{ml} \mathrm{MMC}$, and extracted in the saliva and the duodenal compartments.

\begin{tabular}{|c|c|c|}
\hline $\begin{array}{l}\text { Gastrointestinal } \\
\text { Compartments }\end{array}$ & $\begin{array}{c}\text { Dose } \mu \mathrm{g} / \mathrm{g} \text { dry weight } \\
\text { soil }\end{array}$ & $\begin{array}{l}\text { Number of revertants/ } \\
\text { plate (mean } \pm S E)^{D}\end{array}$ \\
\hline \multirow[t]{5}{*}{ Saliva } & $0^{\mathrm{B}}$ & $314 \pm 2^{\mathrm{E}}$ \\
\hline & $0^{c}$ & $450 \pm 39$ \\
\hline & 1 & $477 \pm 4$ \\
\hline & 10 & $646 \pm 1^{F}$ \\
\hline & 50 & $950 \pm 0^{F}$ \\
\hline Positive ControlA & & $1073 \pm 5^{F}$ \\
\hline \multirow[t]{5}{*}{ Gastric } & $0^{\mathrm{B}}$ & $314 \pm 2^{E}$ \\
\hline & $0^{\mathrm{C}}$ & $390 \pm 7$ \\
\hline & 1 & $394 \pm 4$ \\
\hline & 10 & $417 \pm 2$ \\
\hline & 50 & $381 \pm 9$ \\
\hline Positive Control' ${ }^{\mathrm{A}}$ & & $1073 \pm 5^{\mathrm{F}}$ \\
\hline \multirow[t]{5}{*}{ Duodenal + Bile } & $0^{\mathrm{B}}$ & $314 \pm 2^{E}$ \\
\hline & $0^{c}$ & $356 \pm 5$ \\
\hline & 1 & $374 \pm 60$ \\
\hline & 10 & $687 \pm 101^{F}$ \\
\hline & 50 & $956 \pm 0^{F}$ \\
\hline Positive ControlA & & $1073 \pm 5^{F}$ \\
\hline \multirow[t]{5}{*}{ Sequential } & $0^{B}$ & $314 \pm 2^{E}$ \\
\hline & $0^{c}$ & $393 \pm 6$ \\
\hline & 1 & $419 \pm 4$ \\
\hline & 10 & $428 \pm 4$ \\
\hline & 50 & $440 \pm 15$ \\
\hline Positive ControlA & & $1073 \pm 5^{\mathrm{F}}$ \\
\hline
\end{tabular}

APositive Control for TA102-Mitomycin C $(0.5 \mu \mathrm{g} / \mathrm{plate}) .{ }^{\mathrm{B}}$ Negative control: Filter sterilised water. ${ }^{\mathrm{C} N e g a t i v e ~ c o n t r o l ~ f o r ~ e a c h ~ g a s t r o i n t e s t i n a l ~ c o m p a r t m e n t ~(i . e . ~}$ saliva, gastric, duodenal and sequential). These samples contained un-amended

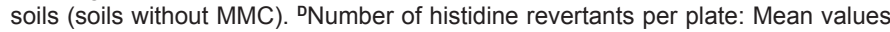
of at least three plates \pm standard error (SE). ENumbers in italic, boldface and underlined represent the number of spontaneous revertants colonies for TA102 (117-530). FNumbers in boldface represent two fold increase or more in the number of revertant colonies over the solvent controls (spontaneous revertants), which was an indication of a significant mutagenic response.

Table 3: The number of reverse mutants of $S$. typhimurium TA102 after exposure to Insch soils amended with MMC and extracted by the sequential and compartmental (saliva, gastric and duodenal) in vitro extraction.

Mutagenicity response of SOS-lux biosensors to MMC amended soil: For soil amended with MMC and extracted in the oral compartment, a significant mutagenic response was measured at concentrations of 1 , 10 and $50 \mu \mathrm{g} \mathrm{MMC/g} \mathrm{dw} \mathrm{soil} \mathrm{for} \mathrm{E.} \mathrm{coli} \mathrm{DPD1718} \mathrm{(Figure} \mathrm{3)} \mathrm{and} \mathrm{E.}$ coli K12C600 (Figure 4). Significant mutagenic responses to 10 and 50 $\mu \mathrm{g} \mathrm{MMC} / \mathrm{g} \mathrm{dw}$ soil were reported for soil extracted in the intestinal compartment and assayed with E. coli DPD1718 (Figure 3) and E. coli K12C600 (Figure 4). The biosensors E. coli DPD1718 and E. coli K12C600 were not significantly induced by MMC in the gastric and the sequential in vitro extractions from Insch soils because MMC denatured at these $\mathrm{pH}$ values (Figures 3 and 4). MMC was more likely to be destroyed because of the acidic $\mathrm{pH}$ of the gastric compartment rather than the gastric enzymes. If the gastric enzymes should have an effect on MMC, this effect should be obvious with the saliva and the duodenal compartments, as both of them have enzymes such as amylase, lipase and pancreatin.

HPLC results for soils amended with MMC: The $\mathrm{pH}$ values of the simulated gastrointestinal compartments had a significant influence $(p<0.05)$ on the measured concentrations of MMC. The concentrations of MMC were $0.69,8.50$, and $49.01 \mu \mathrm{g} \mathrm{MMC/g} \mathrm{dw} \mathrm{soil} \mathrm{for} \mathrm{soil} \mathrm{amended}$ with 1, 10 and $50 \mu \mathrm{g} \mathrm{MMC/g} \mathrm{dw} \mathrm{soil,} \mathrm{respectively,} \mathrm{and} \mathrm{extracted} \mathrm{in} \mathrm{the}$ saliva. For the duodenal compartment, the measured concentrations of MMC were 0.90, 6.32 and $48.32 \mu \mathrm{g} \mathrm{MMC/g} \mathrm{dw} \mathrm{soil.} \mathrm{These} \mathrm{results}$ confirmed that the $\mathrm{pH}$ values of the saliva and the duodenal had no 

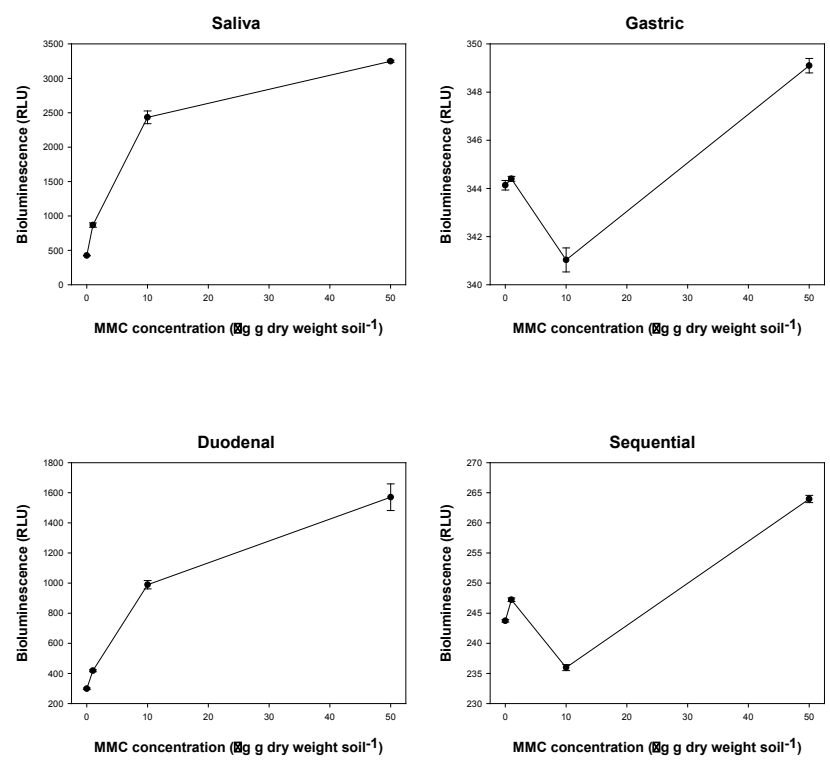

Figure 3: Mutagenicity response of the SOS-lux microbial biosenso Escherichia coli DPD1718 to Insch soils amended with MMC and extracted by the sequential and the compartmental (saliva, gastric and duodenal) in vitro extraction. Error bars represent the standard errors of the mean of triplicate measurements.
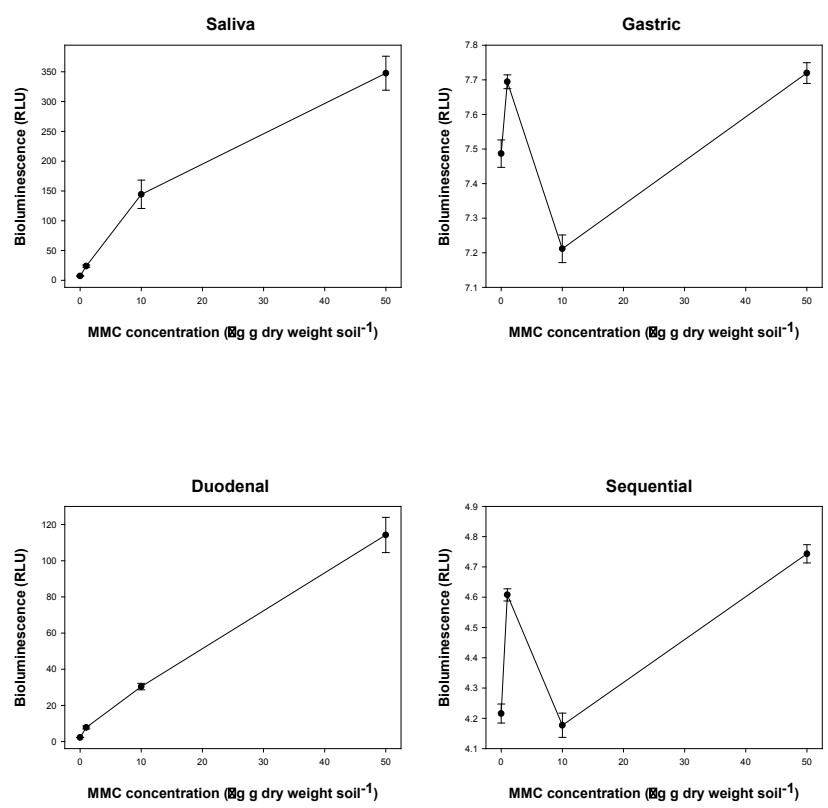

Figure 4: Mutagenicity response of the SOS-Iux microbial biosensor Escherichia coli $\mathrm{K} 12 \mathrm{C} 600$ to Insch soils amended with MMC and extracted by the sequential, and the compartmental (saliva, gastric and duodenal) in vitro extraction. Error bars represent the standard errors of the mean of triplicate measurements.

significant effect on the measured concentrations of MMC. The minute reduction in the measured concentrations of MMC was due to the low $\mathrm{pH}$ value $(4.2 \pm 0.0)$ of Insch soil [11]. For soil extracted in the gastric compartment, the measured concentrations of MMC were $0.35,0.21$, and $0.37 \mu \mathrm{g} \mathrm{MMC/g} \mathrm{dw} \mathrm{soil} \mathrm{for} \mathrm{soils} \mathrm{amended} \mathrm{with} 1,10$ and $50 \mu \mathrm{g}$ $\mathrm{MMC} / \mathrm{g} \mathrm{dw}$ soil, respectively. Similar results were reported for soil extracted in the sequential compartment (the measured concentrations of MMC were $0.50,0.34$ and $0.18 \mu \mathrm{g} \mathrm{MMC/g} \mathrm{dw} \mathrm{soil} \mathrm{for} \mathrm{soils} \mathrm{amended}$ with 1,10 and $50 \mu \mathrm{g} \mathrm{MMC} / \mathrm{g} \mathrm{dw}$ soil, respectively). The acidic $\mathrm{pH}$ of the gastric compartment $(1.1 \pm 0.1)$, and Insch soil $(4.2 \pm 0.0)$ destroyed MMC and caused an enormous reduction in the measured concentrations of MMC.

\section{Discussion}

MMC was selected for this study because it is a highly water soluble chemical acknowledged to induce a response both to the Ames assay and the biosensor [17]. MMC is a natural occurring compound consisting of a pyrrolo (1,2-a) indole ring system with an aziridine ring.MMC is a potent DNA cross-linker, which has a strong ability to crosslink DNA with high efficiency and specificity for the sequence CpG [18]. To interact with DNA, MMC requires enzymatic activation by a one-electron pathway to a semiquinone, or by a two-electron reduction pathway to a hydroquinone [19]. MMC has several biological effects in mammalian cells, such as mutagenesis, stimulation of genetic recombination, selective inhibition of DNA synthesis, chromosome breakage and sister chromatid exchange and induction of the DNA repair system (SOS-response) [18]. The anti-cancer activity of MMC is based upon its covalent binding to DNA after chemical or enzymatic reductive activation [20].

Salmonella strain TA102 was the most sensitive among the Salmonella strains to detect the mutagenicity of MMC. Growth inhibition was observed with the Salmonella strains TA98 and TA100 when exposed to MMC (Table 1). The same results were also reported by Maron and Ames [12], who observed inhibition of growth with TA97, TA98 and TA100 when exposed to $2.5 \mu \mathrm{g} / \mathrm{plate}$ of MMC. Consequently, MMC was adopted as a positive control to assess the number of histidine revertants colonies for TA102 [10,12,21]. There is no doubt that the biosensor yielded rapid results when compared with the Ames assay, and this is widely acknowledged [22,23]. An acknowledged limitation of biosensors is that future developments will require the characterisation and adoption of strong promoters offering genuine relevance with key target receptors [24].

The selection of the particular assay procedures reported was because these were acknowledged to be responsive to MMC, but translation to other chemicals of concern (particularly hydrophobic compounds such as PAHs) may require a new suite of mutagenic responsive sensors and assays. In this study, the biosensor performance and sensitivity was similar to the Ames assay. This has been used to reinforce the merit of rapid screening assays to derive values for human protection. But there is a need to take a wider view. The main challenge is that the data that underpin the human protective strategy must be validated against relevant receptors. Comparing biosensor or Ames derived data with those from animal experiments where injection of the chemical into the animal has occurred may be of limited value. So, before the adoption of protective values or the use of routine screening approaches, users must be confident about the relevance of the adopted data.

The impact of soil borne mutagenic compounds on human receptors is of considerable interest when deriving threshold values that will prove protective [3]. There would be little relevance in simply using a solvent extraction procedure to collect the analyte and then measure the response, because this would not reflect the human bioaccessible fraction [1]. For MMC, there were problems with the stage of the assay procedure that mimicked the conditions of the stomach. The acidic nature of this step oxidised the test compound, and this is likely to 
be a problem with other chemicals of concern. A mutagenic response to MMC was recorded only for soil samples extracted in the oral and the intestinal compartments ( $\mathrm{pH} 6.5 \pm 0.2$ and $7.8 \pm 0.2$, respectively) (Table 3 and Figures 3 and 4). There was no mutagenic response to MMC by the Salmonella assay or the SOS-lux biosensors for the gastric or the sequential in vitro digestion assay, because the compound had been destroyed under the acidic condition $(\mathrm{pH} 1.1 \pm 0.1)$ of the gastric compartment. Even after a buffering step to mediate the $\mathrm{pH}$ value, there was no significant mutagenic response, which was confirmed by chemical analysis (Table 2 ). This concentration should not pose an unacceptable risk to a child ingesting up to $0.6 \mathrm{~g}$ of soil daily for six years contaminated with MMC.

The particular relevance and indeed the focus of this work was that it combined a human bioaccessibility assay with mutagenic testing. Such in vitro assays were developed for inorganic chemicals of concern, but there has been wider translation to other pollutants and mixed contaminants. This bioaccessibility in vitro procedure verifies a relevant environmental interface because this considers the potential pathways through which humans could become exposed to such mutagenic compounds. The question is not about the mutagenicity of soil, but is about the mutagenic nature of compounds that are bioaccessible in the soil. A constraint however, was that a specific stage of the in vitro assay oxidised the analyte. Further refinement of this procedure to adopt less harsh surrogate steps for the stomach and duodenal stage could mitigate this, but detailed correlation would be required against established data.

A key advantage of the application of biosensors is their ability to be deployed to genuine samples [24]. This means that while chromatographic analysis requires extraction, purification, clean-up, potentially derivatisation and then analysis, the biosensor can be used in crude and turbid solutions. This could be exclusively for a mutagenic sensor or for a wider suite of sensors for specific analytes and generic toxicity. Samples could be exposed to a suite of sensors simultaneously, allowing a real time response that could prove valuable for the protection of target receptors at a timescale commensurate with intervention [22]. The sensors could also be fabricated to permit compact analysis and the use of disposable electrodes. Such technologies could transform routine testing and interpretation.

\section{Conclusion}

This study enabled an empirical assessment of a model mutagen borne in soil and its potency on human receptors.

SOS-lux biosensors had numerous practical advantages over the traditional assays, including procedural simplicity, a rapid and unambiguous result, ease of measurement, rapid tabulation of exposure concentration and in vivo analysis without cell disruption. A critical insight for the bacterial SOS system and the regulatory pathway, which is responsible for inducible DNA repair system, is essential for the genetic engineering of these biosensors. This engineering must be placed in parallel with environmental applicability that enables the collection and analysis of relevant environmental samples and complementary chemical characterisation. As mutagenic-based biosensors evolve, the key traits of this study can be translated to ensure relevance and applicability.

\section{Acknowledgment}

The authors would like to thanks Dr. Petra Rettbergand Dr. Ying Zhang for providing the biosensors strains.

\section{References}

1. Oomen AG, Rompelberg CJ, Bruil MA, Dobbe CJ, Pereboom DP, et al. (2003) Development of an in vitro digestion model for estimating the bioaccessibility of soil contaminants. Arch Environ Contam Toxicol 44: 281-287.
2. Alexander M (2000) Aging, bioavailability and overestimation of risk from environmental pollutants. Environ Sci Technol 34: 4259-4265.

3. Ruby MV, Davis A, Schoof R, Eberle S, Sellstone CM (1996) Estimation of lead and arsenic bioavailability using a physiologically based extraction test. Environ Sci Technol 30: 422-430.

4. Lee JH, Mitchell RJ, Kim BC, Cullen DC, Gu MB (2005) A cell array biosensor for environmental toxicity analysis. Biosens Bioelectron 21: 500-507.

5. Gu MB, Chang ST (2001) Soil biosensor for the detection of PAH toxicity using an immobilized recombinant bacterium and a biosurfactant. Biosens Bioelectron 16: 667-674.

6. van der Meer JR, Belkin S (2010) Where microbiology meets microengineering Design and applications of reporter bacteria. Nat Rev Microbiol 8: 511-522.

7. Rettberg P, Baumstark-Khan C, Bandel K, Ptitsyn LR, Horneck G (1999) Microscale application of the SOS-LUX-TEST as biosensor for genotoxic agents. Anal Chim Acta 387: 289-296.

8. Pereira TS, Gotor GN, Beltrami LS, Nolla CG, Rocha JAV (2010) Salmonella mutagenicity assessment of airborne particulate matter collected from urban areas of Rio Grande do Sul State, Brazil, differing in anthropogenic influences and polycyclic aromatic hydrocarbon levels. Mutat Res Genet Toxicol Environ Mutagen 702: 78-85

9. Josephy PD, Gruz P, Nohmi T (1997) Recent advances in the construction of bacterial genotoxicity assays. Mutat Res 386: 1-23

10. Mortelmans K, Zeiger E (2000) The Ames Salmonella/microsome mutagenicity assay. Mutat Res 455: 29-60.

11. Maderova L, Dawson JJC, Paton GI (2010) Cu and Ni mobility and bioavailability in sequentially conditioned soils. Water Air Soil Pollut 210: 63-73.

12. Maron DM, Ames BN (1983) Revised methods for the Salmonella mutagenicity test. Mutat Res 113: 173-215.

13. Vankemmelbeke M, Healy B, Moore GR, Kleanthous C, Penfold CN, et al. (2005) Rapid detection of colicin E9-induced DNA damage using Escherichia coli cells carrying SOS promoter-lux fusions. J Bacteriol 187: 4900-4907.

14. Mehta RC, Hogan TF, Mardmomen S, Ma JK (1988) Chromatographic studies of mitomycin $\mathrm{C}$ degradation in albumin microspheres. J Chromatogr 430: 341 349

15. Rabbow E, Rettberg P, Baumstark-Khan C, Horneck G (2002) SOS-LUX-and LAC-FLUORO-TEST for the quantification of genotoxic and/or cytotoxic effects of heavy metal salts. Anal Chim Acta 456: 31-39.

16. Rettberg P, Bandel K, Baumstark-Khan C, Horneck G (2001) Increased sensitivity of the SOS-LUX-Test for the detection of hydrophobic genotoxic substances with Salmonella typhimurium TA1535 as host strain. Anal Chim Acta 426: 167-173.

17. Alhadrami HA, Paton GI (2013) The potential applications of SOS-lux biosensors for rapid screening of mutagenic chemicals. FEMS Microbiol Lett 344: 69-76.

18. Tomasz M (1995) Mitomycin C: Small, fast and deadly (but very selective). Chem Biol 2: 575-579.

19. Davidov Y, Rozen R, Smulski DR, Van Dyk TK, Vollmer AC, et al. (2000) Improved bacterial SOS promoter::Iux fusions for genotoxicity detection. Muta Res 466: 97-107.

20. Marín D, Pérez P, Teijeiro C, Palecek E (1998) Methods for direct determination of mitomycin $C$ in aqueous solutions and in urine. Biol Proced Online 1: 100106

21. Ames BN, McCann J, Yamasaki E (1975) Methods for detecting carcinogens and mutagens with the Salmonella/mammalian microsome mutagenicity test. Mutat Res 31: 347-364.

22. Melamed S, Elad T, Belkin S (2012) Microbial sensor cell arrays. Curr Opin Biotechnol 23: 2-8.

23. Baumstark-Khan C, Rabbow E, Rettberg P, Horneck G (2007) The combined bacterial Lux-Fluoro test for the detection and quantification of genotoxic and cytotoxic agents in surface water: Results from the "Technical Workshop on Genotoxicity Biosensing". Aquat Toxicol 85: 209-218.

24. Azrilawani A, Moore EJ (2009) Comparison of cell-based biosensors with traditional analytical techniques for cytotoxicity monitoring and screening of polycyclic aromatic hydrocarbons in the environment. Analy Lett 42: 1-28. 